\title{
Research on Status Quo and Countermeasures of Cold Chain Logistics of Agricultural Products in Hunan Province*
}

\author{
Bo Wei \\ Hunan Modern Logistics College \\ Changsha, China
}

\begin{abstract}
This paper conducts a comprehensive investigation and analysis of the development status and main problems of cold chain logistics of agricultural products in Hunan Province. The countermeasures for the development of cold chain logistics for agricultural products are put forward from the aspects of planning and layout of cold chain logistics facilities for agricultural products, construction of cold chain logistics systems, innovation in the circulation mode of farmer-business interconnection, and application of new technologies and equipment for cold chain logistics.
\end{abstract}

Keywords-agricultural products; cold chain logistics; countermeasures of development

\section{INTRODUCTION}

Hunan is a large agricultural province and has always enjoyed such reputations as "land of fish and rice", "hometown of pigs" and "vegetable basket base". With the increase in the upriver circulation of agricultural products, Hunan needs to apply advanced technologies such as low-temperature freezing in production, processing, transportation, storage, and sales. In particular, the regional large-scale output of fresh produce and the increase in off-season sales urgently require Hunan Province to develop cold-chain logistics of agricultural produce to ensure that fresh produce is always at a suitable temperature environment necessary to maintain its quality, maximum ensuring product quality, reducing product loss, and improving efficiency. Due to the lag in the development of the cold chain, Hunan's agricultural exports account for a small proportion, $80 \%$ of which are primary products and lack competitiveness in the international market. Especially in recent years, as developed countries continue to raise access standards for imported agricultural products, related quality, technology, and green barriers have become important obstacles that restrict the export of agricultural products in our province. Therefore, the development of cold chain logistics is not only the need for the upriver logistics of agricultural products in Hunan Province, but also the need to ensure the healthy and stable growth of the agricultural industry in Hunan Province. At the same time, it will also help to improve the quality of agricultural products for export, break through trade barriers, and strengthen the international competitiveness of

*Fund: Project carried out by the Hunan Provincial Department of Education in 2018 (Project No. 18C1563). agricultural products in Hunan Province.

\section{DeVElopment Status OF COLD Chain Logistics FOR Agricultural Products in Hunan Province}

\section{A. The Infrastructure of Cold Chain Logistics Is Gradually Improved}

Hunan's existing cold chain logistics infrastructure is mainly cold stores and refrigerated warehouses. As of now, the total existing cold storage capacity in Hunan Province is 2.14 million tons, of which 1 million tons are cold stores and 1.14 million tons are refrigerated warehouses. The province has a capacity of 500,000 tons of cold stores under construction and a capacity of 730,000 tons of refrigerated warehouses under construction. The capacity of cold storage has increased significantly compared to 2015 . With the support of provincial special funds, the full coverage of cold chain logistics counties (cities) was basically achieved, and infrastructure conditions were improved.

\section{B. The Quality of Cold Chain Circulation of Agricultural Products Has Steadily Improved}

In recent years, the quality of cold chain logistics in Hunan Province has improved, the cold chain circulation rate and refrigerated transport rate have increased significantly, and the wear rate has continued to decline. According to the sample survey and statistics of typical cold chain logistics enterprises, the cold chain circulation rates of meat, aquatic products, fruits, and vegetables are $31.6 \%, 32.3 \%, 23.2 \%$, and $20.4 \%$, respectively, the refrigerated transportation rates were $42.3 \%$, $45.4 \%, 26.2 \%$, and $21.6 \%$, respectively, and the damage rates were $14.2 \%, 13.5 \%, 14.1 \%$, and $16 \%$.

\section{Preliminary Results Have Been Achieved in the Construction of a Standardized System}

The two cities of Xiangtan and Huaihua have been listed by the Ministry of Commerce and the National Standards Commission as pilot cities for the cold chain distribution of agricultural products. The standardization and informatization of cold chain logistics focusing on fresh agricultural products such as meat, aquatic products, fruits and vegetables, have achieved preliminary results. 
specializing in cold chain logistics technology and cold chain logistics equipment research and development in Hunan Province. The research and development foundation of cold chain logistics technology is weak, and the technical personnel of cold chain logistics are scarce. products has increased, and the proportion of off-season sales has gradually increased, which has promoted farmers' income. Cold chain logistics enterprises have laid the foundation for precision poverty alleviation by absorbing the employment of the poor and transferring the land of the poor.

\section{THE MAIN PROBLEMS IN THE DEVELOPMENT OF COLD CHAIN LOGISTICS OF AGRICULTURAL PRODUCTS IN HUNAN PROVINCE}

\section{A. Insufficient Scale and Unreasonable Structure of Cold Chain Infrastructure}

The total capacity of Hunan's existing cold storage is 2.14 million tons, which is far behind Henan Province in central China, with a gap of 1.26 million tons. Compared with the developed provinces of China's cold chain logistics (such as Guangdong and Shandong), the gap in cold storage capacity is even larger, with differences of 1.93 million tons and 3.11 million tons, respectively. The average cold storage capacity of major provinces (30 provinces) across the country is 1.77 million tons. The cold storage capacity in Hunan Province only exceeded the national average of 370,000 tons. Among them, there are more large-scale productive cold storages and fewer small-scale retail cold storages. There are more cold storages for meat, and less cold storages for vegetables, fruits, agricultural and sideline products, and flowers.

\section{B. The Layout Planning of the Cold Chain Logistics Industry Needs to Be Improved}

The warehouses in Hunan Province engaged in cold chain logistics are mainly concentrated in Changsha, Zhuzhou and Xiangtan. Changsha cold storage capacity accounts for about $50 \%$ of the entire Hunan cold storage capacity, but the scale of the cold chain logistics distribution center is relatively small. The lack of scientific planning on the location, scale design, and radiation range of existing cold storage infrastructures has led to oversupply of cold storage infrastructures in some areas, resulting in low utilization of cold storage capacity. The fierce price war has led to vicious competition among enterprises, and cold chain logistics companies have suffered losses for years.

\section{The Level of Cold Chain Logistics Equipment and Technology Is Relatively Backward}

The cold chain logistics equipment in Hunan Province is outdated and the overall quantity is small. These devices are mostly used for the freezing and storage of meat and fish, with single functions and high energy consumption. Moreover, information technology is lacking, and intelligence and modernization are not high. Origin pre-cooling technology and equipment are lacking, and there is a serious shortage of refrigerated trucks and deepfreeze during transportation, which cannot guarantee the entire cold chain transportation, and it is prone to "chain breakage". There is a shortage of enterprises

\section{Standardization of Cold Chain Logistics Needs to Be Strengthened Urgently}

Because there are many types of cold chain logistics products, there are large differences, and different cold chain products have different requirements on temperature and vehicle configuration. The standardization of cold chain logistics in Hunan is still at the stage of standardization of terms, including standardization of basic concepts of cold chain logistics activities, standardization of cold chain logistics activities terms, and standardization of cold chain logistics technology equipment and facilities terms. Many substantive issues have not yet been addressed. Despite the implementation of the cold chain logistics standardization pilot, the construction of a standardized system is still a short board. The logistics legislative system is complicated, and the construction of a cold chain logistics standardization system is very difficult, but it is very urgent.

\section{COUNTERMEASURES TO PROMOTE THE DEVELOPMENT OF COLD CHAIN LOGISTICS OF AGRICULTURAL PRODUCTS IN HUNAN PROVINCE}

\section{A. Optimizing the Planning and Layout of Cold Chain Logistics}

According to the requirements of Hunan Province 's "Thirteenth Five-Year Plan" logistics industry development plan and the scale and distribution of refrigerated and frozen products in Hunan Province, relevant departments analyze the product flow, flow direction, and technical requirements for storage and transportation, comprehensively consider the conditions of residents' consumption level, consumption habits, and transportation location to build a cold chain logistics network with one hub, three bases, and unique coverage.

Relevant departments should establish cold-chain logistics core hubs with Changsha, Zhuzhou, and Xiangtan urban agglomerations as the focus, and focus on building cold-chain logistics distribution centers for meat, aquatic products, seafood, fruits, and vegetables, and establish and improve urban cold-chain logistics distribution terminal networks, vigorously developing international cold chain logistics business. Relevant departments should build a cold chain logistics base around Dongting Lake with Yueyang, Changde and Yiyang as the center, focus on the development of characteristic cold chain logistics, and establish a complete aquatic product and pork cold chain distribution system. The southern Hunan cold chain logistics base with Hengyang City, Chenzhou City, and Yongzhou City as the nodes connects the Pearl River Delta and ASEAN, undertakes the functions of import and export of agricultural products and the export of local characteristic agricultural products, and focuses on the development of meat, fruit and vegetable cold chain distribution systems. It is necessary to establish a western Hunan cold chain logistics base with Huaihua City, Shaoyang 
City, Loudi City, Xiangxi Tujia and Miao Autonomous Prefecture, and Zhangjiajie City as junctions, linking the Chengdu-Chongqing urban agglomeration and the YunnanGuizhou Economic Zone, and radiating the policies and geographical advantages of the southwest, focusing on the development of cold chain distribution systems for fruits and vegetables, beef and mutton, especially cold chain distribution of citrus, kiwi and bayberry.

In Hunan's agricultural and sideline products characteristic counties, such as meat, aquatic products, fruits, vegetables, tea, and others, the government can promote the construction of county-level cold chain logistics facilities and carry out cold chain to the countryside. In combination with industrial poverty alleviation, a number of cold chain facilities will be constructed. The government can develop integrated cold chain logistics, establish a cross-region long-distance cold chain logistics system, promote anti-season sales, and achieve full coverage of the cold chain of characteristic agricultural products.

\section{B. Speeding up the Construction of Infrastructure for Cold Chain Logistics}

The government should encourage and support the production and processing of various types of refrigerated and frozen products, cold chain logistics enterprises and agricultural cooperatives, etc. to build facilities such as refrigerated, refrigerated and fresh-keeping warehouses that meet the needs of modern circulation and consumption, promote the application of new cold chain technologies and new products, in particular strengthen the construction of production capacity of pre-cooling, fresh-keeping processing, fresh-keeping transportation, and refrigerated sales terminals of "first $1 \mathrm{~km}$ " and "last $1 \mathrm{~km}$ " to effectively solve the problem of "broken chains" in the cold chain.

The government should support the construction of lowtemperature common distribution centers around cities, support the construction of low-temperature logistics zones for fresh produce wholesale markets, and support the construction of cold storage in central wholesale markets, regional wholesale markets, large supermarkets, and retail chains. The government needs to support the construction of a group of pre-cold collection and distribution centers for agricultural products with functions such as pre-cooling, refrigeration, primary processing, and transportation, accelerate the standardization and transformation of existing public cold storage closed delivery platforms, halls, and shelves, promote the construction of intelligent high-end cold storage facilities such as fresh storage, variable temperature storage, airconditioned storage, and three-dimensional automatic cold storage, focus on supporting the upgrading and reconstruction of existing old cold storage, upgrading and transformation of ordinary warehouses in ordinary logistics parks and highway freight stations, and setting up cold chain logistics operation zones.

\section{Speeding up the Construction of the Entire Cold Chain Logistics System}

The government should actively build a cold chain logistics system for meat, frozen foods, fruits and vegetables and aquatic products, support the construction of automated threedimensional cold storage, and the construction of regional distribution centers in urban areas in Hunan Province, cooperate with third-party logistics enterprises to increase the dry-branch quick-frozen food cold-chain transportation lines, establish strict temperature monitoring and quality tracing systems in the circulation, storage and distribution links, establish a "non-broken chain" cold chain logistics system with intelligent temperature controlled storage, cold chain transportation, processing and distribution, terminal sales, and full traceability, implement the national mandatory standards for temperature control of perishable foods, explore the formulation of pre-chilling operation specifications, technical requirements, and cold chain logistics information technology requirements for perishable agricultural products, speed up the application of standardized pallets, turnover boxes, refrigerated containers and other transport units in the cold chain logistics transportation, warehousing and distribution processes, implement the whole process monitoring and quality tracing system for fresh produce, and accelerate the formation of cold chain logistics technical standards and temperature control requirements covering the entire chain, organize cold chain logistics enterprises to carry out standardized pilot demonstrations and strengthen the promotion and implementation of relevant standards, carry out standardized common delivery vehicles of "unified model, unified technology, unified standard, and unified management".

\section{Encouraging Cold Chain Logistics Enterprises to Use New Technologies and Innovative Models}

It is necessary to encourage cold chain logistics enterprises, scientific research institutions, industry associations, etc. to participate in the construction of cold chain logistics product monitoring, traceability systems, big data platforms, and trading platforms, to fully utilize new technologies such as radio frequency identification (RFID), intelligent temperature control technology, and blockchain technology to improve the intelligence and information collection capabilities of cold chain logistics facilities, to encourage enterprises to actively use new technological means to improve the quality and level of cold chain logistics services. to promote joint cold chain distribution in cities, and to develop new business models such as "cold chain distribution + chain retail", "fresh e-commerce + cold chain home delivery", "production base + e-commerce + cold chain express + smart vegetable cabinets" and other new business models, to promote the development of "Internet +" cold chain logistics, to develop "internet + vehicle-cargo matching", "internet + equipment leasing", "internet + multimodal transport", and to cultivate a new type of integrated cold chain format of "cold storage resource platform + transport capacity pool". 
chain logistics service system of "full temperature control, sound standards, green safety, and wide application", and gradually form a cold chain infrastructure network with a reasonable layout, wide coverage and smooth connection. Only this can fully improve the quality of life of residents, ensure the safety of various agricultural products, and benefit people's livelihood.

\section{REFERENCES}

[1] Wang Jianqiang. Research on the Innovation Strategy of Agricultural Products Cold Chain Logistics Development Model under the Background of "Internet +" [J]. China Market, 2019, 09. (in Chinese)

[2] Cui Zhongfu. Strengthening Cold Chain Logistics to Promote the Upgrading of Agricultural Product Circulation [J]. Logistics \& Material Handling, 2018, 10. (in Chinese)

[3] Guo Yanan, Hu Yuankun. Research on the Development Status and Countermeasures of Agricultural Products Cold Chain Logistics in China [J]. Logistics Engineering and Management, 2018, 02. (in Chinese)

[4] Wang Qingyan. The Experience of Foreign Cold Chain Logistics Development and Its Enlightenment to China [J]. Economic \& Trade Update, 2016, 07. (in Chinese) sized cold chain logistics enterprises, and support existing small and medium-sized cold chain logistics enterprises in the transportation, warehousing, freight forwarding, intermodal, express, and urban distribution industries to improve their functions and extend services. Through asset reorganization, business integration and process re-engineering, it will innovate personalized service models, expand cold chain logistics service networks, meet the needs of diversified logistics markets, and guide the transformation and upgrading of traditional logistics enterprises. Agricultural product production and sales enterprises, farmer cooperatives and third-party cold chain logistics enterprises should be encouraged to carry out long-term cooperation to realize the socialization, specialization, scale and intensification of cold chain logistics.

It is necessary to actively introduce domestic and foreign leading enterprises, to strengthen open investment and to introduce large-scale domestic and foreign cold chain logistics service integrators to set up regional logistics centers and regional distribution centers in Hunan province, thus improving the capacity of international cold chain resource allocation.

\section{CONCLUSION}

In recent years, with the rapid development of China's economy, people's living standards have been increasing, the consumption capacity of urban and rural residents has been continuously improved, and residents' demand for quality and differentiation of agricultural products has become higher and higher. Only after cold chain logistics links such as precooling after production, sorting and processing, frozen storage, refrigerated transportation and distribution, and frozen sales can the quality of agricultural products be guaranteed. The development of cold chain logistics for agricultural products must build a modern cold chain logistics system that is "full chain, networked, strict standards, traceable, new models, and efficient" in line with national conditions and provincial conditions. Hunan Province should steadily establish a cold 